\title{
Somatic and psychiatric co-morbidity in Primary Care patients in Spain
}
A. Lobo ${ }^{\star, \star \star}$
R. Campos*
G. Marcos*
J. García-Campayo ${ }^{\star \star, \star \star \star}$
A. Campayo*,**
R. López-Antón**
MJ. Pérez-Echeverría*

* Departamento de Psiquiatría. Hospital Clínico Universitario, Universidad de

Zaragoza

** Instituto Aragonés de Ciencias de la Salud
${ }^{* * *}$ Hospital Universitario Miguel Servet SPAIN

\begin{abstract}
Background: There is limited information on the subject of co-morbidity of general medical conditions (GMCs) and general psychiatric disturbance in primary care (PC).

Methods: A representative sample $(\mathrm{n}=1559)$ of adult PC patients was examined in a two-phase screening. Standardized screening instruments were used, including the Standardized Polyvalent Psychiatric Interview (SPPI). ICD-10 research criteria were used for psychiatric diagnosis, and ICPC-2 for medical diagnosis.

Results: Most co-morbidity cases had depressive (120 cases, $28.1 \%$ ) or anxiety/neurotic disorders (217 cases, 50.9\%). In support of the working hypothesis, the proportion of patients with several medical diagnoses was significantly higher among the cases, and logistic regression showed that the probability of being a psychiatric case increased with each medical diagnosis done by the primary care physician $(\mathrm{OR}=2.46$; IC 1.66-3.66, $\mathrm{p}<0.001)$. Moderate/severe cases were significantly more frequent among the depressed group (91 cases, $75.9 \%$ ), but were also common in the anxiety/neurosis group (52 cases, $24 \%$ ), the between groups differences in disability being non-significant. The distribution of both affective and neurotic disorders by specific ICPC- 2 categories suggests preferential associations.

Conclusion: In PC, the probability of having a co-morbid psychiatric diagnosis doubles with each medical diagnosis. Anxiety/neurotic disorders, and not only depressive disorders, are relevant co-morbid psychiatric categories in this setting.
\end{abstract}




\section{Introduction}

It is almost universally recognized by now that psychiatric morbidity in primary care (PC) is a burden from the public health perspective ${ }^{1}$. However, the attitude of primary care physicians (PCPs) in relation to this reality varies, and may influence considerably the pace at which they adapt to it. This is an area of special interest in countries with strong PC systems ${ }^{2}$, such as Spain, particularly when there is official emphasis in liaison programs with $\mathrm{PC}^{3}$. The problem of under-detection and under-treatment of psychiatric morbidity in PC has not been solved ${ }^{4}$ despite increasing evidence both of the negative outcome even in subsyndromal morbidity, ${ }^{5}$ and of the effectiveness of different types of interventions, particularly in cases of depression ${ }^{6}$.

Somatisation in PC has stirred much interest and is one of the problems related to under-detection $^{7}$. On the contrary, with the exception of depression ${ }^{8}$, there is considerable less information on the issue of psychiatric disturbances co-morbid with general medical conditions (GMC's). Furthermore, some studies found the association of depression only with severe, but not with the mild or moderate physical illness which is commonly found in $\mathrm{PC}^{9}$, and unmet needs in this area of research have been discussed ${ }^{4}$. Similarly, the association of anxiety disturbance and medical conditions needs new studies, since most research has been completed in the community ${ }^{10}$, and only rarely in PC samples ${ }^{11}$.

This report is part of the Zaragoza Study of psychiatric morbidity in PC, which included some data on the relationships of somatic and psychiatric disturbances ${ }^{12}$. The three objectives are: i) to describe the general characteristics of co-morbidity; ii) to test the hypothesis that there is a relationship between GMC's and psychiatric morbidity, and specifically, that the number of somatic diagnoses increases the probability of having a co-morbid psychiatric diagnosis; and iii) to explore the possibility that compared to the problem of cases of co-morbid depression, the magnitude of the problem of cases of co-morbid anxiety and other neurotic conditions might be of similar relevance.

\section{Methods}

These have been previously described ${ }^{12}$. In summary, a representative sample $(\mathrm{n}=1559)$ of consecutive patients aged 20 years or older attending eight randomly selected health centres with a new episode of illness were examined using two-phase screening. In phase 1, standardized Spanish versions of the following instruments were administered by lay interviewers: the General Health Questionnaire 28-Items (GHQ-28) ${ }^{13}$, the Mini-Mental Status Examination ${ }^{14}$, the CAGE questionnaire ${ }^{15}$ and a simple screening instrument for the detection of abuse of other substances.

All probable cases identified in phase-1, and a proportion of probable non-cases $(15 \%)$ were examined by research clinicians in phase 2 with the Standardized Polyvalent Psychiatric Interview or SPPI ${ }^{16}$. The SPPI was built on the Clinical Interview Schedule, assesses the individuals in a multi-axial schema and fulfils standards of feasibility, reliability and validity (kappa, range 0.70 0.94). It includes subjective ratings of disability ( 0 to 4 ) for each of 10 reported symptoms in the main sections (kappa, range 0.86-0.94). A global "disability index" (DI) is obtained by adding up the scores, but scores of 2 or more in any symptom are considered to be clinically significant. 
Psychiatric cases in this study (defined according to 'global' SPPI criteria, scores 2, 3 or 4 for mild, moderate and severe, respectively) were diagnosed by the research psychiatrists $(\mathrm{kappa}=0.88)$ according to ICD-10 research criteria, adapted to use in the assessment of medical patients ${ }^{17}$. In this report, only the first diagnosis will be considered and, specifically, cases having both anxiety and depressive syndromes were classified as "depressed" when depression was the predominant syndrome. The somatic diagnoses were done by the primary care physicians (PCPs) according to the International Classification of Health Problems in Primary Care (ICPC-2, WONCA), blind to the psychiatric assessment. Co-morbidity was defined as the co-occurrence of a medical diagnosis (ICPC-2), caseness (SPPI) and psychiatric diagnosis (ICD-10).

The statistical analysis included logistic regression to study the association between psychiatric cases and number of medical diagnoses.

\section{Results}

Table I compares the demographic characteristics of the whole sample, the 427 cases identified and 165 non-cases selected. Thirty five cases diagnosed in phase-2 were "low scorers" in phase- 1 and, on the contrary, 55 non-cases in the second assessment had been "high scorers" in the initial screening. Compared to the non-cases, there were significantly higher proportions of women among the cases; the latter tended to be younger than the non-cases, but the differences were not statistically significant. However, the proportion of the elderly (65 years or more) was significantly lower among the cases (51 cases, $11.9 \%$; 32 noncases, $\left.19.4 \% ; \chi^{2}=4.596, \mathrm{p}=0.032\right)$.

Most somatic illnesses were not severe, and there was considerable spreading of diagnosis in each ICPC-2 category. However, there were significant differences in the

Table I

Demographic characteristics of the total sample, non-cases and psychiatric cases.

\begin{tabular}{|c|c|c|c|}
\hline & Total $(\mathrm{N}=1559)$ & Non-cases $(\mathrm{N}=165)$ & Cases $(\mathrm{N}=427)$ \\
\hline \multicolumn{4}{|l|}{ Gender } \\
\hline Men & $711(45.6)$ & $78(47.3)$ & $136(31.9)$ \\
\hline \multirow[t]{2}{*}{ Women } & $848(54.4)$ & $87(52.7)$ & $291(68.1)$ \\
\hline & & \multicolumn{2}{|c|}{$\chi^{2}=12.26$, d.f. $=1, p<0.001$} \\
\hline \multicolumn{4}{|c|}{$\pi$} \\
\hline Mean \pm s.d. & $45.9 \pm 17.2$ & \multicolumn{2}{|c|}{$t=0.68$, d.f. $=590, p=0.49$} \\
\hline \multicolumn{4}{|l|}{ Marital status } \\
\hline Single & $386(24.8)$ & $51(30.9)$ & $91(21.3)$ \\
\hline Married & $1018(65.3)$ & $101(61.2)$ & $286(67.0)$ \\
\hline Divorced & $37(2.4)$ & $3(1.8)$ & $20(4.7)$ \\
\hline Widow & $116(7.4)$ & $10(6.1)$ & $29(6.8)$ \\
\hline \multirow[t]{2}{*}{ Other } & $2(0.1)$ & - & $1(0.2)$ \\
\hline & & \multicolumn{2}{|c|}{$\chi^{2}=8.174$, d.f. $=5, p=0.085$} \\
\hline \multicolumn{4}{|l|}{ Educational Level } \\
\hline Illiterate & $33(2.1)$ & $1(0.6)$ & $14(3.3)$ \\
\hline Compulsory partial education & $884(56.7)$ & $88(53.3)$ & $242(56.6)$ \\
\hline Compulsory full education & $228(14.6)$ & $35(21.2)$ & $92(21.6)$ \\
\hline Higher vocational training & $272(17.5)$ & $21(12.7)$ & $61(16.5)$ \\
\hline \multirow[t]{2}{*}{ University/Polytechnic } & $142(9.1)$ & $20(12.2)$ & $31(7.2)$ \\
\hline & & \multicolumn{2}{|c|}{$\chi^{2}=9.968$, d.f. $=7, p=0.190$} \\
\hline
\end{tabular}


distribution of medical categories in the two sub-samples (Table II).

Table III shows the distribution of cases by ICD-10 diagnostic group. As expected, most of them had affective disorders or anxiety disorders grouped in the heterogeneous category of neurotic disorders. For comparative purposes in this report, all cases of mood

Table II

ICPC-2 (WONCA) First diagnoses: psychiatric cases and non-cases.

\begin{tabular}{|c|c|c|c|c|c|c|}
\hline & \multicolumn{2}{|c|}{ Non-cases } & \multicolumn{2}{|c|}{ Cases } & \multirow{2}{*}{$\begin{array}{c}\text { Proportion } \\
\text { Difference } \\
\text { C.l. }(\%)\end{array}$} & \multirow{2}{*}{ ? } \\
\hline & $\mathrm{N}$ & $\%$ (C.I.) & $\mathrm{N}$ & $\%$ (C.I.) & & \\
\hline $\begin{array}{l}\text { A - General And Unspecified } \\
\text { Symptoms }\end{array}$ & 6 & $3.6(1.3-7.7)$ & 63 & $14.8(11.6-18.5)$ & $(-16,-7)$ & $\mathrm{p}=0.0001$ \\
\hline $\begin{array}{l}\text { B - Blood, Blood Forming Organs, } \\
\text { Lymphatics, Spleen }\end{array}$ & 5 & $3.0(1.0-0.7)$ & 2 & $0.5(0.1-1.7)$ & $(-5,1)$ & $\mathrm{p}>0.005$ \\
\hline D - Digestive & 12 & $7.3(3.4-12.3)$ & 49 & $11.5(8.6-14.9)$ & $(-9,1)$ & $\mathrm{p}>0.005$ \\
\hline F - Eye & 4 & $2.4(0.6-6.1)$ & 2 & $0.5(0.1-1.7)$ & $(-1,4)$ & $\mathrm{p}=0.04$ \\
\hline H - Ear & 3 & $1.8(0.4-5.2)$ & 4 & $0.9(0.24-2.3)$ & $(-1,3)$ & $p>0.005$ \\
\hline K - Circulatory & 12 & $7.3(0.38-12.4)$ & 25 & $5.9(3.9-8.6)$ & $(-3,6)$ & $p>0.005$ \\
\hline L - Musculoskeletal & 39 & $23.6(17.3-30.9)$ & 83 & $19.4(15.8-23.5)$ & $(-3,12)$ & $p>0.005$ \\
\hline N - Neurological & 5 & $3.0(1.0-0.7)$ & 22 & $5.2(3.3-7.7)$ & $(-5,1)$ & $\mathrm{p}>0.005$ \\
\hline P - Psychological & - & - & 35 & $8.2(5.8-11.2)$ & - & - \\
\hline R - Respiratory & 52 & $31.5(24.5-39.2)$ & 84 & $19,7(16.0-23.8)$ & $(4,20)$ & $\mathrm{p}=0.0022$ \\
\hline S - Skin & 13 & $7.9(4.2-13.1)$ & 17 & $4.0(2.3-6.3)$ & $(-1,8)$ & $\mathrm{p}>0.005$ \\
\hline $\begin{array}{l}\text { T - Endocrine, Metabolic And } \\
\text { Nutritional }\end{array}$ & 3 & $1.8(0.4-5.2)$ & 3 & $0.7(0.1-2.0)$ & $(-1,3)$ & $\mathrm{p}>0.005$ \\
\hline U - Urology & 6 & $3.6(1.3-7.7)$ & 26 & $6.1(4.0-8.8)$ & $(-6,1)$ & $p>0.005$ \\
\hline $\begin{array}{l}X \text { - Female Genital System } \\
\text { (Including Breast) }\end{array}$ & 5 & $3.0(1.0-0.7)$ & 12 & $2.8(1.4-4.8)$ & $(-2,4)$ & $\mathrm{p}>0.005$ \\
\hline Total & & $\begin{array}{l}100 \\
81, d . f .=17,1\end{array}$ & $\begin{array}{l}427 \\
0.001\end{array}$ & 100 & & \\
\hline
\end{tabular}

Table III

Distribution of ICD-10 psychiatric diagnoses in primary care cases.

\begin{tabular}{lcc} 
Diagnosis (ICD-10) N = 427 & $\mathrm{N}$ & $\%$ (C.I.) \\
\hline Organic mental disorder & 9 & $2.1(1.0-3.9)$ \\
Mental and behavioural disorders due to psychoactive substance use & 26 & $6.1(4.0-8.8)$ \\
Schizophrenia, schizotypal and delusional disorders & 9 & $2.1(1.0-3.9)$ \\
Mood [affective] disorders & 120 & $28.1(23.9-32.6)$ \\
$\quad$ Mild depressive episode & $24(5.6)$ & \\
Moderate depressive episode & $38(8.9)$ & \\
Severe depressive episode without psychotic symptoms & $4(1)$ & \\
Other depressive episodes & $5(1.1)$ & \\
Dysthymia & $49(11.5)$ & \\
Neurotic, stress-related and somatoform disorders & 244 & $57.2(52.3-61.9)$ \\
Panic disorder [episodic paroxysmal anxiety] & $8(1.9)$ & \\
Phobic anxiety disorders and others & $14(3.3)$ & \\
Generalized anxiety disorder & $71(16.6)$ & \\
Mixed anxiety and depressive disorder & $69(16.2)$ & \\
Adjustment disorders & $55(12.9)$ & \\
Somatoform disorders & $27(6.3)$ & \\
Behavioural syndromes associated with physiological disturbances & 19 & $4.4(2.7-6.8)$ \\
and physical factors & & \\
\hline
\end{tabular}


disorders have been included in the group of "depression" ( $\mathrm{n}=120)$ and all cases of the neurotic category, with the exception of somatoform disorders, in the group of "anxiety and neurotic disorders" ( $\mathrm{n}=217)$. As expected, the proportion of moderate/severe cases (SPPI scores 3 or 4) was significantly more frequent in the depressed group (91 cases, $75.9 \%$ ), but 52 cases of anxiety/neurosis $(24 \%)$ were also considered to be moderate/severe $\left(\chi^{2}=85.10\right.$ d.f. $\left.=1, p<0.001\right)$. The disability index in depressive disorders $(\mathrm{DI}=5.26 \pm 4.16)$ was higher than in anxiety disorders (DI $=2.96 \pm 3.11$ ), the differences being statistically significant $(\mathrm{t}=$ $5.735, \mathrm{p}<0.001)$. However, the degree of disability in the moderate/severe level was not significantly different in both diagnostic categories (DI $=6.02 \pm 4.08$ in the first group; and DI $=4.88 \pm 3.62$ in the anxiety/neurosis group; $\mathrm{t}=1.722 ; \mathrm{p}=0.088$ )

In support of the working hypothesis, we found a significantly higher proportion of patients with two or more medical diagnoses among the cases (Table IV). Furthermore, in support of the specific hypothesis, logistic regression analysis showed that controlling by age and sex, the probability of being a psychiatric case increases with each medical diagnosis done by the PCP $(\mathrm{OR}=2.46$; IC 1.66-6.36, $\mathrm{p}<0.001)$.

Table V shows the distribution of the most frequent categories of psychiatric diagnosis (ICD-10) by medical diagnostic group. Among both, affective disorders and neurotic disorders, the most frequent medical illnesses were grouped in the categories "general and unspecified symptoms", musculoskeletal and respiratory diseases. In relation to this, Table VI shows the likelihood (OR) of having mood disorders or neurotic disorders by each of the most frequent medical diagnostic categories, after controlling for the remaining somatic categories. Mood disorders were significantly associated with both "general and unspecified symptoms" and digestive diseases. However, the association of both diagnostic, medical categories was stronger with the neurotic disorders, particularly in the category of digestive diseases, but there was also a significant association with musculoskeletal and respiratory diseases.

Table IV

Number of medical diagnoses (ICPC-2) in psychiatric cases and non-cases.

\begin{tabular}{lccc} 
Medical Diagnosis & Non-cases $(\mathrm{N}=165)$ & Cases $(\mathrm{N}=427)$ & Total \\
\hline One Medical Diagnosis & $138(83.6 \%)$ & $286(67 \%)$ & 424 \\
Two or more Medical Diagnosis & $27(16.4 \%)$ & $141(33 \%)$ & 168 \\
\hline
\end{tabular}

$\chi^{2}=16.24$ d.f. $=1, p<0.001$

Table V

Likelihood of having mood or neurotic/anxiety disorders among ICPC-2 Categories.

\begin{tabular}{lcrrr} 
& \multicolumn{2}{c}{ Mood Disorders } & \multicolumn{2}{c}{$\begin{array}{c}\text { Neurotic/ Anxiety } \\
\text { Disorders }\end{array}$} \\
\hline & OR & IC & OR & IC \\
\hline A - General And Unspecified Symptoms & 4.6 & $2.5-8.5$ & 12.2 & $6.6-22.7$ \\
D - Digestive & 3.4 & $1.6-7$ & 19.8 & $9.8-40.3$ \\
L - Musculoskeletal & 1.5 & $0.8-2.7$ & 8.2 & $4.7-14.0$ \\
R - Respiratory & 1.1 & $0.6-2.0$ & 9.0 & $5.2-15.5$ \\
\hline
\end{tabular}




\section{Discussion}

In support of the general hypothesis, our data support an association between GMCs and psychiatric morbidity: the proportion of patients with multiple medical diagnoses was significantly higher in the cases, when compared with the non-cases. This finding could not be attributed to an aging population, since the proportion of the elderly was significantly lower among the cases. Furthermore, in support of the specific hypothesis, logistic regression analysis showed that, controlling by age and sex, the probability of having a co-morbid, psychiatric diagnosis doubles with each medical diagnosis done by the PCP $(\mathrm{OR}=2.46)$.

Anxiety (28.1\%) and depression (50.9\%) were the most frequent disturbances in comorbidity cases, and this confirms the relevance of both types of disorder in PC settings ${ }^{18}$. There is abundant evidence about the potential of specific medical diseases such as cerebro-vascular disease ${ }^{19}$, or diabetes $^{20}$ to increase the risk of psychiatric morbidity, and specifically depression. Some studies have also found an association between depression and $\mathrm{GMCs}^{18}$, but others reported the association only with severe, and not with the mild or moderate physical illness which is commonly seen in $\mathrm{PC}^{9}$.

Similarly, there is limited evidence about the co-morbidity of anxiety disturbance and medical conditions in PC samples ${ }^{11}$. Our study showing an association of predominantly mild GMCs and psychiatric disturbances, in particular anxiety and depression, adds to the existing evidence on the co-morbidity issue in PC. While this report was not specifically designed to unravel the direction of the association, the data showing that the probability of having a co-morbid psychiatric diagnosis increases with the number of medical diagnoses is consistent with a causal relationship.
Independent of causal mechanisms, the association of GMCs and psychiatric morbidity has considerable interest from a public health perspective. In this study both severe medical illness and severe psychiatric problems were rare $(6.7 \%$ of cases of depression; and $0.5 \%$ of cases of anxiety). However, the size of the problem of co-morbid psychiatric disturbance is quite considerable, and measures of disability suggest its clinical relevance. We are aware that the disability index used in this study is solely based on a subjective assessment, but self-reports of disability have been found to be feasible and reliable ${ }^{21}$. Since the problem of under-detection in PC has not yet been solved ${ }^{4,18}$, this study suggests that the screening for psychiatric morbidity should not be limited to potential somatisers $^{12}$, but should also be extended to patients diagnosed with somatic conditions by their PCP, and particularly to patients with multiple medical diagnoses. We can not argue about the generalisability of the findings, since important differences in PC morbidity have been documented between countries ${ }^{18}$ that cannot necessarily be attributed to a "category fallacy" ${ }^{22}$. Different PC systems may have different needs ${ }^{1}$, but the findings in this study are certainly relevant in Spain, and may also suggest similar studies in other countries.

This study also explored the possibility that some ICPC-2 medical categories might be more frequently associated with psychiatric morbidity, but several factors limit considerably the interpretation of findings. The spreading of somatic diagnosis makes difficult to count with rather large, homogeneous groups of disorders, and diagnostic categories such as "general and unspecified symptoms" may point to somatization problems, that is, to primarily psychiatric rather than medical diagnoses ${ }^{12}$. Still, data suggesting an association between digestive illness and both depression and anxiety/ neurotic illness; or the association between both musculoskeletal 
and respiratory illness and anxiety/neurotic illness may warrant new studies in the future. Similarly, the description of psychopathological profiles in this sample might offer some clues for future research. Psychopathological analysis in similar settings have suggested that depressed patients endorse easier somatic symptoms of depression when they have GMCs, and improvement in detection may come when somatic symptoms of depression have been considered ${ }^{8}$.

In a context of many studies in the literature emphasazing the consequences of depression co-morbid with medical illness, the last objective in this study was to look at the possibility that the magnitude of the problem of co-morbid anxiety and other neurotic conditions might be of similar relevance. First, anxiety and neurotic illness $50.9 \%$ of cases) were more frequent than depressive disorders (28.1\%). Second, while moderate or severe cases were significantly more frequent in the last category, they were similarly disabling in both conditions, and occurred in a substantial proportion of the anxiety cases (24\%). And third, while differences between the depression and the anxiety diagnostic categories are suggested here in the type and frequency of association with somatic illness, no conclusions may be reached at this stage of the research. Therefore, this study suggests that much enquiry needs to be done also in relation to co-morbid anxiety, since no compelling data have been found to indicate that the magnitude and/or implications of the problem are radically different from the problem of depression in PC.

Some other limitations in the study should also be addressed. We have used a simple categorization of co-morbidity, but we agree that standardization of the definition and assessment is needed to facilitate comparison between studies ${ }^{23}$. Furthermore, while we are not trying to report prevalence of co-morbidity, it might be higher than observed in this study, since a proportion of the non-studied patients in phase- 2 might be false negative cases left out of the analysis. On the other hand, we have used for this analysis only the first psychiatric diagnosis, but psychiatric comorbidity should be targeted for future studies: 38 cases of "depression" (31.6\%) had concomitant anxiety syndromes, and the potential negative implications of this psychiatric co-morbidity have been suggested by previous authors ${ }^{18,24}$. Finally, in studying the association between number of medical diagnoses and psychiatric morbidity, we did not control for factors such as severity of medical illness, but we can not make the assumption that all medical disorders have similar severity and harmful implications.

\section{Acknowledgements}

This research was supported by the following grants: a) P CM-3/89, from the Consejo Asesor de Investigación (CONAI) from de Diputación General de Aragón; b) Network REPEP G03/128 and Network REMTAP RD06/0011, from the Instituto de Salud Carlos III, Ministerio de Sanidad, Madrid, Spain.

The authors acknowledge the contribution of Dr. Leticia Gutiérrez-Galve for her technical assistance.

\section{References}

1. Goldberg D. Psychiatry and primary care. World Psychiatry 2003 ; 2(3): 153-157.

2. Gunn J, Diggens J, Hegarty K, Blashki G. A systematic review of complex system interventions designed to 
increase recovery from depression in primary care. BMC Health Serv Res 2006; 6: 88.

3. Gobierno de Aragón. Plan estratégico 2002-2010 de atención a la Salud Mental en la Comunidad Autónoma de Aragón [Web Page]. 2002; Available at http://portal.aragob.es/. (Accessed January 2007).

4. Charlson M, Peterson JC. Medical comorbidity and late life depression: what is known and what are the unmet needs? Biol Psychiatry 2002; 52(3): 226-235.

5. Lyness JM, Heo M, Datto CJ et al. Outcomes of minor and subsyndromal depression among elderly patients in primary care settings. Ann Intern Med 2006; 144(7): 496-504.

6. Katon WJ, Schoenbaum M, Fan MY et al. Cost-effectiveness of improving primary care treatment of late-life depression. Arch Gen Psychiatry 2005; 62(12): 1313-1320.

7. Kroenke K, Rosmalen JG. Symptoms, syndromes, and the value of psychiatric diagnostics in patients who have functional somatic disorders. Med Clin North Am 2006; 90(4): 603-626.

8. Yates WR, Mitchell J, Rush AJ et al. Clinical features of depressed outpatients with and without co-occurring general medical conditions in STAR*D. Gen Hosp Psychiatry 2004; 26(6): 421-429.

9. Berardi D, Leggieri G, Ceroni GB et al. Depression in primary care. A nationwide epidemiological survey. Fam Pract 2002; 19(4): 397-400.

10. Sareen J, Cox BJ, Clara I, Asmundson GJ. The relationship between anxiety disorders and physical disorders in the U.S. National Comorbidity Survey. Depress Anxiety 2005; 21(4): 193-202.

11. Stein MB, Roy-Byrne PP, Craske MG et al. Functional impact and health utility of anxiety disorders in primary care outpatients. Med Care 2005; 43(12): 1164-1170.

12. Lobo A, Garcia-Campayo J, Campos R, Marcos G, Perez-Echeverria MJ. Somatisation in primary care in Spain: I. Estimates of prevalence and clinical characteristics. Working Group for the Study of the Psychiatric and Psychosomatic Morbidity in Zaragoza. Br J Psychiatry 1996; 168(3): 344-348.

13. Lobo A, Perez-Echeverria MJ, Artal J. Validity of the scaled version of the General Health Questionnaire (GHQ-28) in a Spanish population. Psychol Med 1986; 16(1): 135-140.

14. Lobo A, Ezquerra J, Gomez Burgada F, Sala JM, Seva Diaz A. [Cognoscitive mini-test (a simple practical test to detect intellectual changes in medical patients)]. Actas Luso Esp Neurol Psiquiatr Cienc Afines 1979; 7(3): 189-202.
15. Altisent R. La deteccion precoz de la enfermedad alcohólica: cuestionarios CAGE y CBA frente a marcadores biológicos. Zaragoza: Universidad de Zaragoza; 1986.

16. Lobo A, Campos R, Perez-Echeverria MJ et al. A new interview for the multiaxial assessment of psychiatric morbidity in medical settings. Psychol Med 1993; 23(2): 505-510.

17. Malt UF, Huyse FJ, Herzog T, Lobo A, Rijssenbeek AJ. The ECLW Collaborative Study: III. Training and reliability of ICD-10 psychiatric diagnoses in the general hospital setting--an investigation of 220 consultants from 14 European countries. European Consultation Liaison Workgroup. J Psychosom Res 1996; 41(5): 451-463.

18. Ustun TB, Sartorius N. Mental illness in general health care: an international study. Chichester: Published on behalf of the World Health Organization by Wiley, 1995.

19. Robinson RG. The neuropsychiatry in the age of subespecialization (Editorial). Eur J Psychiatry 2006; 20(2): 61-65.

20. de Jonge P, Roy JF, Saz P, Marcos G, Lobo A. Prevalent and incident depression in community-dwelling elderly persons with diabetes mellitus: results from the ZARADEMP project. Diabetologia 2006; 49(11): 2627 2633.

21. Von Korff M, Ustun TB, Ormel J, Kaplan I, Simon GE. Self-report disability in an international primary care study of psychological illness. J Clin Epidemiol 1996; 49(3): 297-303.

22. Simon GE, Goldberg DP, Von Korff M, Ustun TB. Understanding cross-national differences in depression prevalence. Psychol Med 2002; 32(4): 585-594.

23. Krishnan KR, Delong M, Kraemer H et al. Comorbidity of depression with other medical diseases in the elderly. Biol Psychiatry 2002; 52(6): 559-588.

24. Andrade L, Caraveo-Anduaga JJ, Berglund P et al. The epidemiology of major depressive episodes: results from the International Consortium of Psychiatric Epidemiology (ICPE) Surveys. Int J Methods Psychiatr Res 2003; 12(1): 3-21.

Address for correspondence:

Hospital Clínico Universitario

Servicio de Psiquiatría. Planta 3

Avda. San Juan Bosco, 15

50009 Zaragoza

SPAIN

Telephone \#: +34 976551167

Fax \#: +34 976765788

e-mail address: alobo@unizar.es 